\title{
The application of whole-body vibration in physiotherapy - A narrative review
}

\author{
M Stania ${ }^{1}$, G Juras $^{2}$, K Słomka $^{2}$, D Chmielewska ${ }^{1}$, P Król ${ }^{1}$ \\ ${ }^{1}$ Department of Physiotherapy Basics, Jerzy Kukuczka Academy of Physical Education, Katowice, Poland \\ ${ }^{2}$ Department of Human Motor Behavior, Jerzy Kukuczka Academy of Physical Education, Katowice, Poland
}

Received: July 23, 2015

Accepted: March 13, 2016

\begin{abstract}
Whole-body vibration (WBV) training is a very popular kind of practice in sport, fitness and physiotherapy. This work reviews the current knowledge regarding the use and effectiveness of WBV in the physiotherapy. The discrepancies between different authors' results are probably due to divergence in WBV training protocols. The paperwork clearly showed that despite its ultimate effects, exercises on a vibration platform are safe, feasible, and well tolerated by patients with different disorders. This narrative review should help physiotherapists verify therapy programs regarding patients' exposure to WBV.
\end{abstract}

Keywords: vibration, physiotherapy, patients, whole-body vibration, medicine

\section{Introduction}

For a few years now, more modern and effective methods of conventional interventions have been sought and considered in physiotherapy including the use of whole-body vibration (WBV). Several reports have been published regarding the impact of vibration on human tissues and systems $(55,56)$. The biological response of particular types of tissues to applied mechanical vibrations depends on several variables, including the vibration variables, the physiological properties of tissues and individual variation (31).

One of the most thoroughly examined biological effects of WBV is an increase in the activity of striated muscles as detected with surface electromyography $(34,54)$. Mechanical vibrations cause a specific myotatic reflex, commonly referred to in literature as a tonic vibration reflex (TVR) (24). Other biological effects of WBV include stimulation of bone formation processes (39), blood vessel dilation, improvement in circulation and oxygen uptake (53), increased testosterone and growth hormone secretion and a decrease in cortisol concentrations (35), increase in intramuscular temperature (17), flexibility improvement (65), and a decrease in circulating glucose (20). It should be emphasized though that not all the reports so far published have confirmed the beneficial influence of vibration training.

Beneficial functional and morphological adaptations observed following the application of adequately adjusted mechanical vibrations encouraged researchers to include these vibrations in physiotherapy and the rehabilitation process. Cardinale and Wakeling (12) emphasize that sedentary, injured and elderly people with impaired muscle activation capabilities are those who benefit the most from WBV training applications. The authors

\footnotetext{
Corresponding author: Magdalena Stania, PhD

Department of Physiotherapy Basics, Jerzy Kukuczka Academy of Physical Education Mikołowska 72a, 40-065 Katowice, Poland

Phone: +48 3220751 29; Fax: +48 3225110 97; E-mail: m.stania@awf.katowice.pl
} 
suggest that WBV may be of benefit in some rehabilitation programs. The most recent studies indicate that WBV therapy should be considered for use in early in-bed rehabilitation in the intensive care unit $(5,10)$. There are also reports regarding the use of resistance exercises combined with vibration exposure for the prevention of muscle atrophy associated with prolonged periods of supine positioning (3).

\section{Methods}

\section{Search methods}

The aim of the present paper is to present the most recent research reports, published after 2007, analyzing the use and effectiveness of WBVs in the physiotherapy of neurological, pediatric, geriatric, and orthopedic patients. The presentation should help physiotherapists verify therapy programs regarding patients' exposure to WBV. The mechanisms of the action of WBV are beyond the scope of this paper. A search was conducted using the following databases: PubMed, Medline, Scopus, EBSCOHost, ScienceDirect, and Web of Science (last search on the 4th February 2016). Keywords including WBV, vibration training, physiotherapy, stroke, cerebral palsy, spinal cord injury, Parkinson's disease, multiple sclerosis (MS), Duchenne muscular dystrophy, older adults or the elderly, osteoporosis, anterior cruciate ligament (ACL) reconstruction, osteoarthritis, arthroplasty, and low back pain were used in various configurations. Reference lists of all retrieved articles were manually checked for additional studies. This is a narrative review, and the authors were free to choose the subset of related high-quality clinical studies based on their experience.

\section{Selection criteria}

Articles were checked for relevant content and were included based on the following criteria: the publication language was English; examined WBV (not locally applied vibration); the publications were published after 2007; and conference abstracts and proceedings were excluded.

\section{Nervous System Diseases}

Neurophysiological response to acute vibration exposure is associated with spinal reflexes (resulting in a TVR), muscle tuning mechanism, neuromuscular aspects, and central motor command (16). Different training protocols have been used in neurological patients (Table I). However, the results regarding the application of vibration training in patients with central and peripheral nervous system remain equivocal.

WBV has been used in the treatment of patients with Parkinson's disease $(1,14,22,26$, 32). Patients able to cope with OFF periods were qualified for the study (1). Despite different training protocols, the above-mentioned research studies exhibit quite a few common characteristics, i.e., the application of stochastic vibrations $(14,26,32)$, high amplitude vibrations, i.e., 7-14 mm (1, 22), and $13 \mathrm{~mm}$ (14) in 5 training sessions of 60-s duration (1, $14,26,32)$. A popular tool to measure the results of a therapy in a unified manner is the Unified Parkinson's Disease Rating Scale $(1,22)$. The obtained results confirm a significant improvement in motor symptoms compared to baseline measurements $(1,14,22,32)$. Longterm follow-up by Ebersbach et al. (22) revealed sustained improvement in the functional status of Parkinson's patients. However, all the above authors emphasize that they did not 


\begin{tabular}{|c|c|c|c|c|c|}
\hline 窇 & 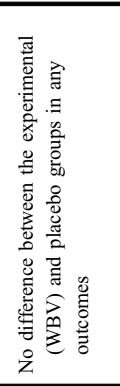 & 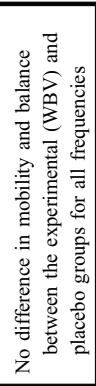 & 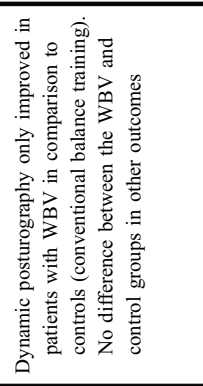 & 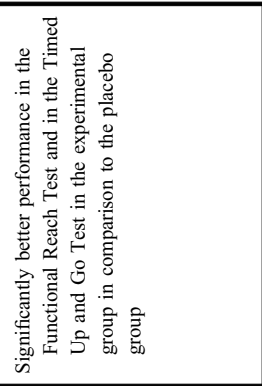 & 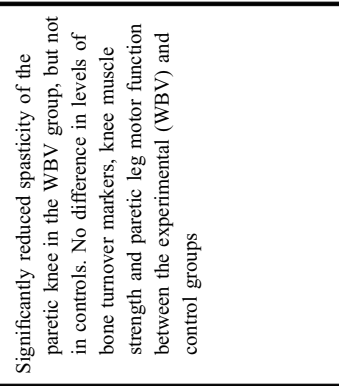 \\
\hline 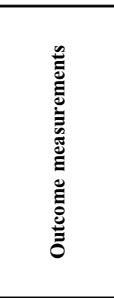 & 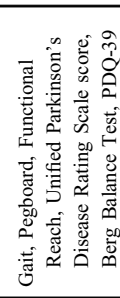 & 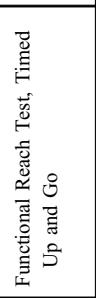 & 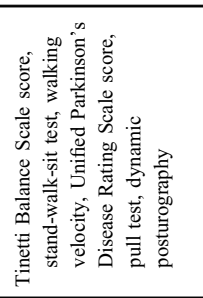 & 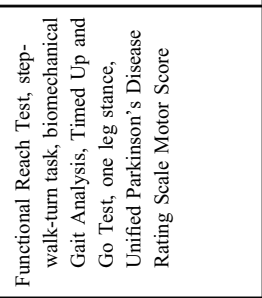 & 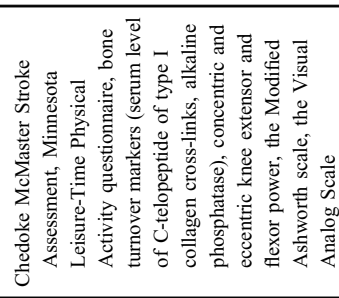 \\
\hline 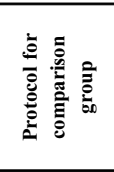 & 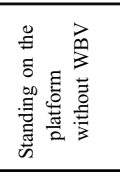 & 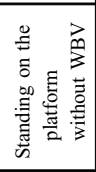 & 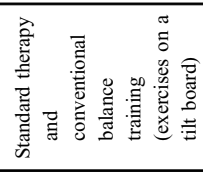 & 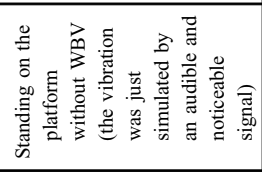 & 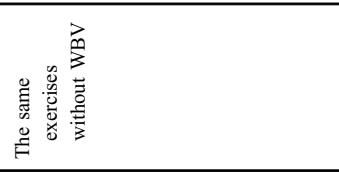 \\
\hline 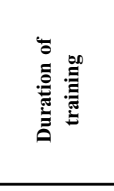 & 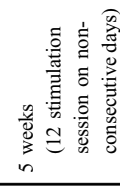 & 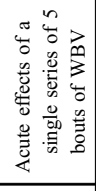 & 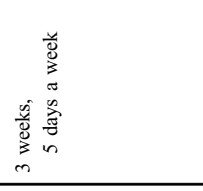 & 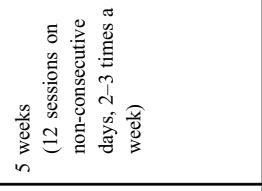 & 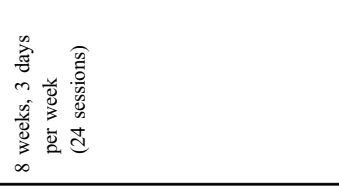 \\
\hline 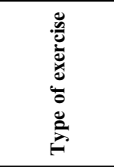 & 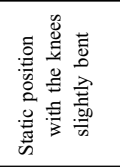 & 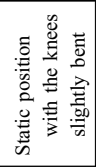 & 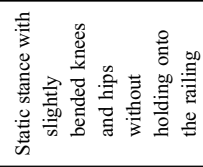 & 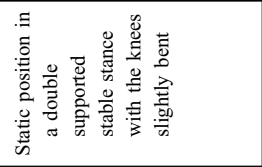 & 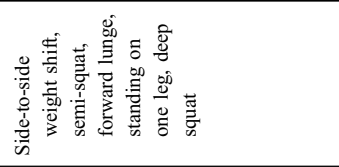 \\
\hline 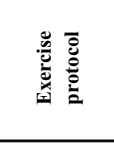 & 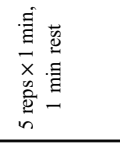 & 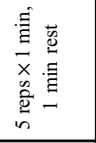 & 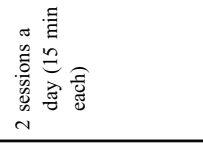 & 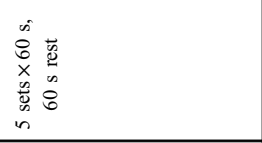 & 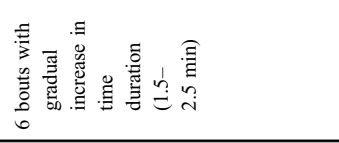 \\
\hline 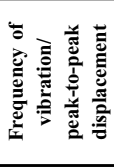 & 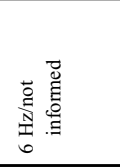 & 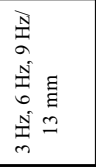 & 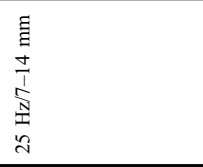 & $\begin{array}{l}\text { 具 } \\
0 \\
\text { N } \\
\text { N } \\
0\end{array}$ & 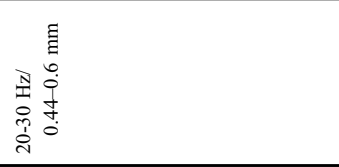 \\
\hline 竞 & 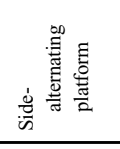 & 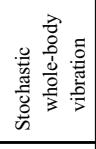 & 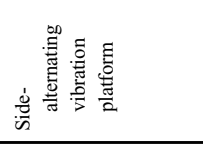 & 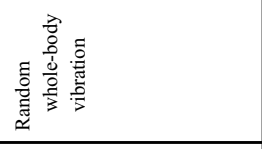 & 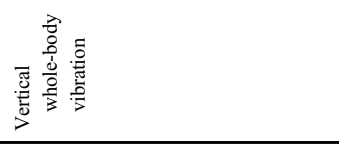 \\
\hline 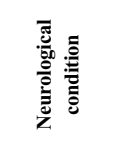 & 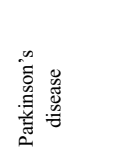 & 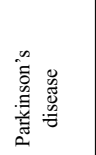 & 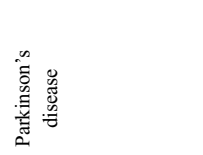 & 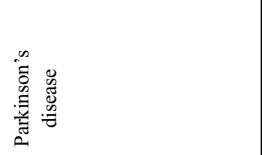 & 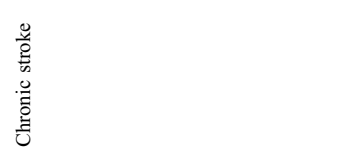 \\
\hline 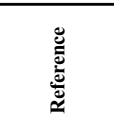 & 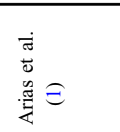 & 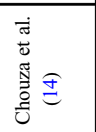 & 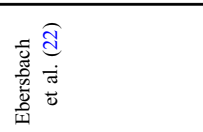 & 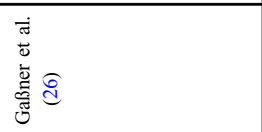 & 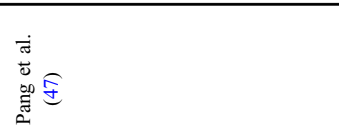 \\
\hline
\end{tabular}




\begin{tabular}{|c|c|c|c|c|}
\hline 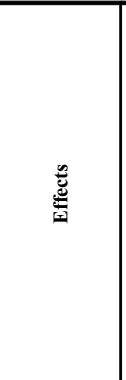 & 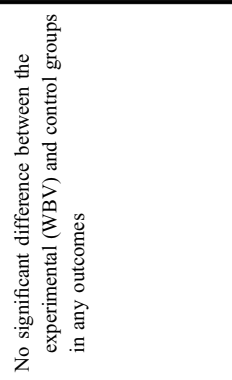 & 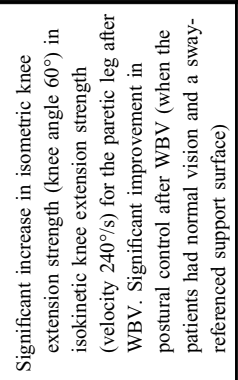 & 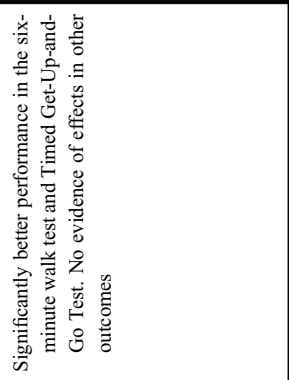 & 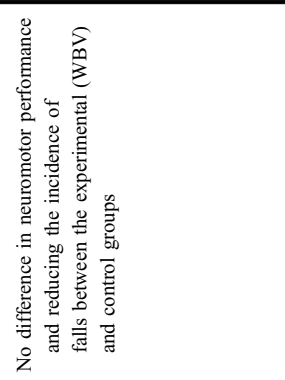 \\
\hline 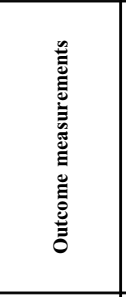 & 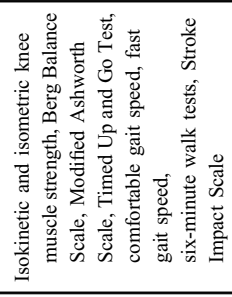 & 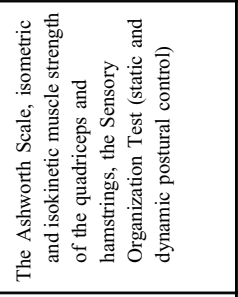 & 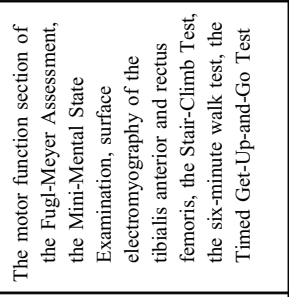 & 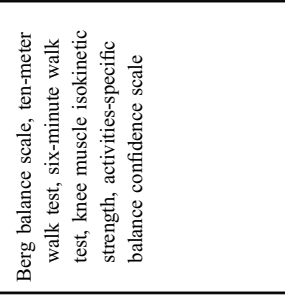 \\
\hline 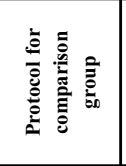 & 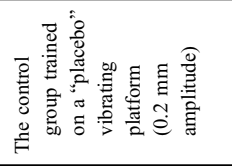 & 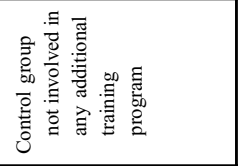 & 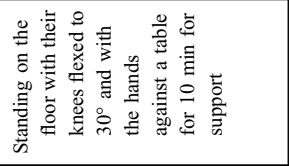 & 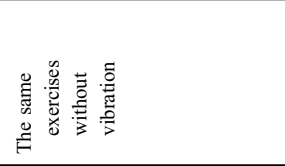 \\
\hline 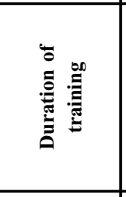 & 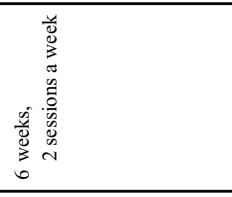 & 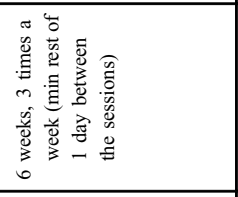 & 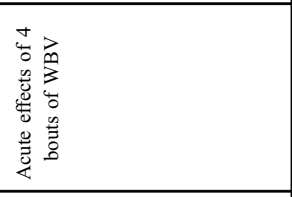 & 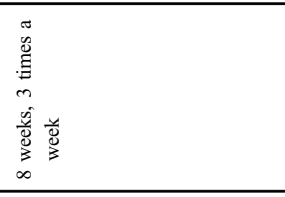 \\
\hline 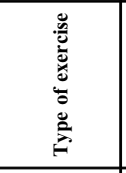 & 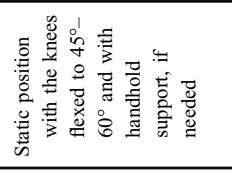 & 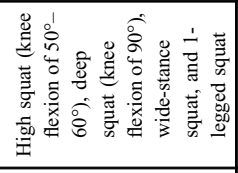 & 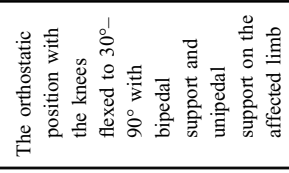 & 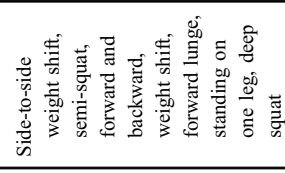 \\
\hline 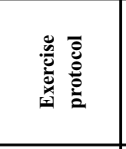 & 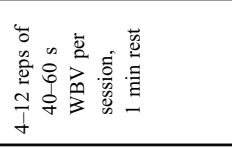 & 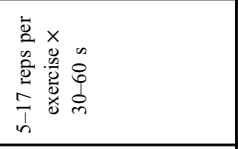 & 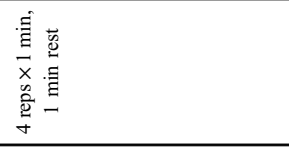 & 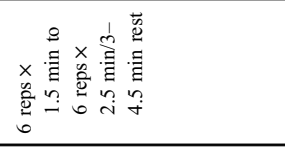 \\
\hline 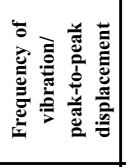 & 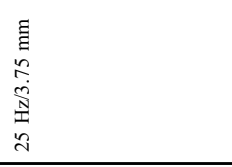 & 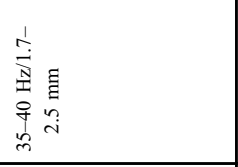 & $\begin{array}{l}\mathbb{1} \\
\stackrel{1}{N} \\
\stackrel{N}{N} \\
8 \\
\end{array}$ & 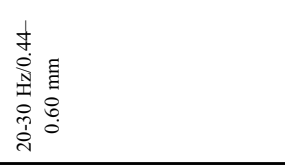 \\
\hline 竞 & 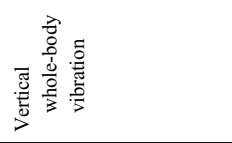 & 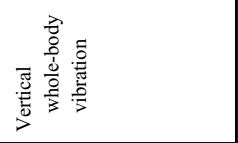 & 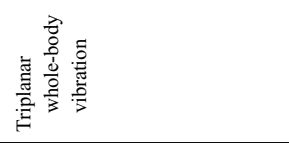 & 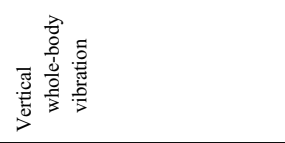 \\
\hline 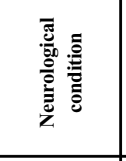 & 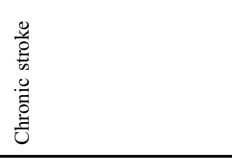 & 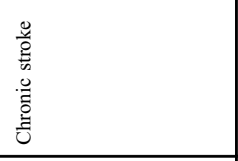 & 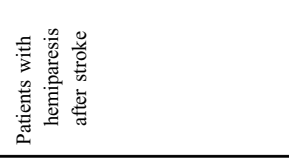 & 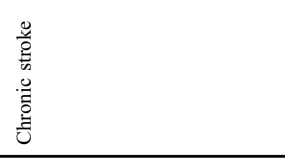 \\
\hline 这 & 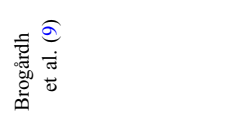 & 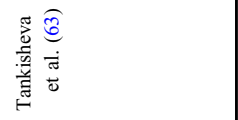 & 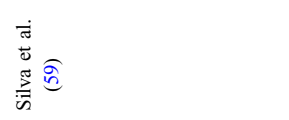 & 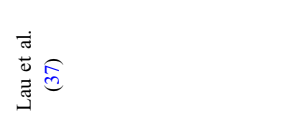 \\
\hline
\end{tabular}




\begin{tabular}{|c|c|c|}
\hline 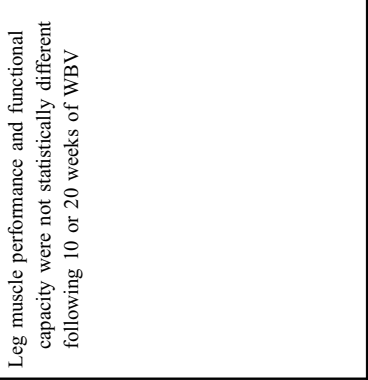 & 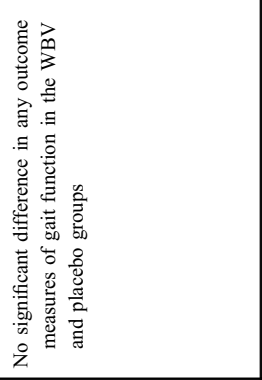 & 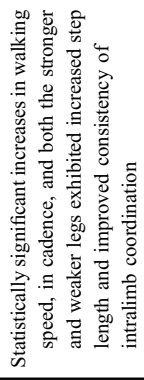 \\
\hline 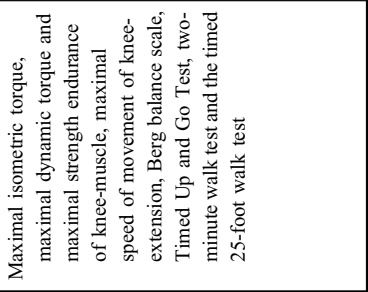 & 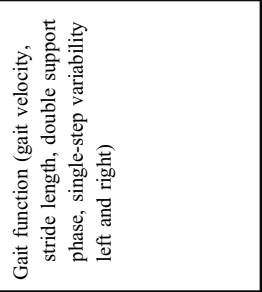 & 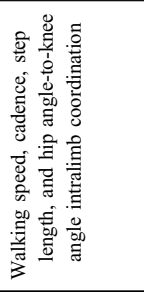 \\
\hline 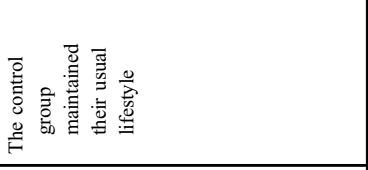 & 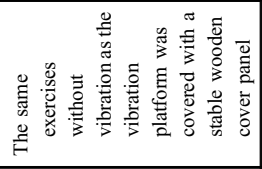 & 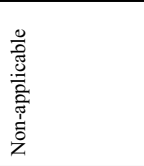 \\
\hline 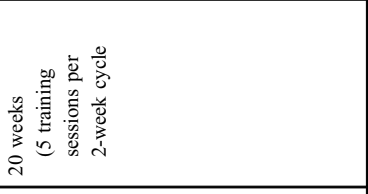 & $\begin{array}{l}n \\
\frac{\pi}{\pi} \\
3 \\
m \\
m\end{array}$ & 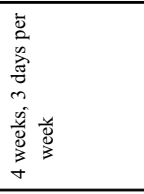 \\
\hline 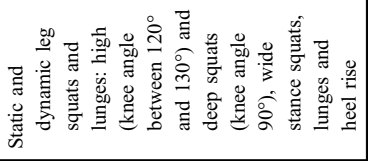 & 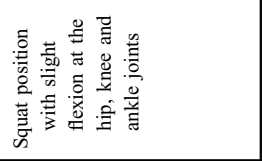 & 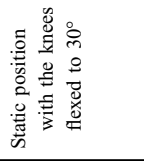 \\
\hline 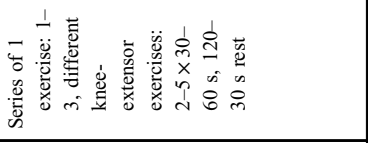 & 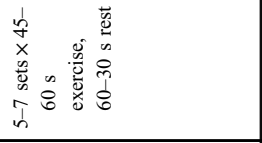 & 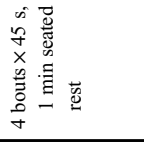 \\
\hline 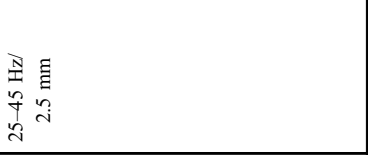 & 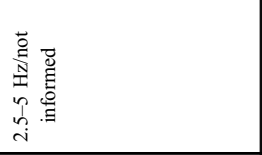 & 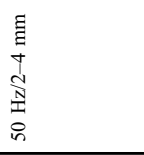 \\
\hline 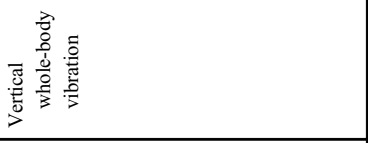 & 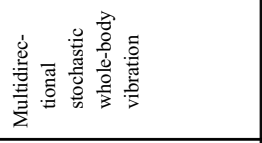 & 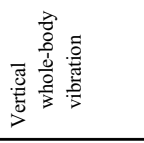 \\
\hline 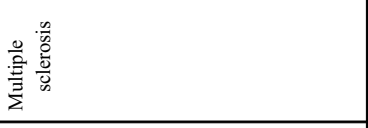 & 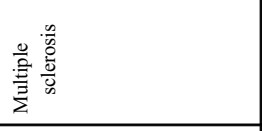 & 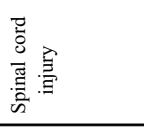 \\
\hline 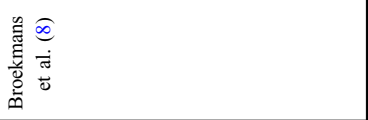 & 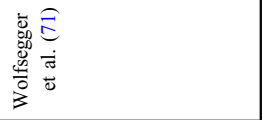 & 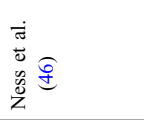 \\
\hline
\end{tabular}


find any superior effect of WBV in patients with Parkinson's disease compared to non-WBV groups $(1,14,26)$, and a group with conventional balance training (22). Arias et al. (1) concluded that the reported amelioration of Parkinsonian symptoms attributed to vibration was most probably due to a placebo response.

Since mechanical vibrations might affect reflex activity through influence on spinal motor neuron excitability (45), they have also been used to reduce spasticity in patients with cerebral palsy (21), motor-incomplete spinal cord injury $(45,46)$, and post-stroke mild to moderate motor impairment $(9,37,47)$. However, in the study of Tankisheva et al. (63) muscle spasticity was not affected by vibration. Motor function in spastic structures was usually assessed by the Ashworth Scale (9, 58, 63), Berg Balance Scale (9, 37), or threedimensional gait analysis $(21,46)$.

The most recent study (38) indicates that WBV exercises do not pose any substantial cardiovascular hazard in individuals with chronic stroke. The investigators of randomized controlled trials designed to examine the effects of WBV in post-stroke populations mainly used vertical WBV programs $(37,47)$ spanning $6-8$ weeks $(9,28,37,47,63)$; the study subjects mostly underwent vibration 3 times a week $(37,47,63)$ at frequencies of $20-50 \mathrm{~Hz}$ $(37,47,59,63)$. Patients with chronic stroke (onset $\geq 6$ months) and with mild to moderate disability were qualified for the investigations $(9,37,40,47)$. They were medically stable and able to stand independently with or without aids for at least $1.5 \mathrm{~min}$ (47). Most of the reports indicate that WBV has little $(47,59,63)$ or no effect $(9,37,40)$ on function improvement in hemiplegic patients. However, the most recent randomized controlled pilot study suggests that WBV training can reduce knee hyperextension in stroke patients (28).

Vibration platforms are more and more often used in rehabilitation centers for patients with MS, although the results of research studies have not unequivocally confirmed the effectiveness of WBV in those patients (8). Individuals with mild to moderate impairment were enrolled in these studies; Expended Disability Status Scale scores were 4.3 (8), 5.5 (15), and 3.5 (41). Jackson et al. (29) attempted to establish the optimum WBV frequency in patients with MS. They did not reveal significant differences between the effects of 2- and 26-Hz WBV on lower extremity muscle strength; however, based on the obtained results, the authors have suggested that the 26- $\mathrm{Hz}$ WBV with vibration amplitude of $6 \mathrm{~mm}$ seems more beneficial for persons with MS (29). Other researchers working with MS patients used the following vibration parameters: $2-20 \mathrm{~Hz} / 2 \mathrm{~mm}(23), 40 \mathrm{~Hz} / 2 \mathrm{~mm}(58)$, and $25-45 \mathrm{~Hz} /$ $2.5 \mathrm{~mm}$ (8); WBV was applied several times a week for 20 weeks (8), 8 weeks (41), and 3 weeks (15). The discrepancies between the results obtained in MS patients are considerable: Ebrahimi et al. (23) concluded that low intensity exercise and WBV training have some positive effects on functional and physical indices, but no beneficial impact on the quality of life and fatigue; Claerbout et al. (15) noted significant improvement in lower extremity muscle strength, but no significant functionality changes; and Broekmans et al. (8) did not observe any beneficial effect of WBV on leg muscle performance and function. The most recent study (67) suggests that 12 weeks of WBV training protocol are feasible with low drop-out rate of $11.1 \%$ and high compliance of $90 \%$ for ambulatory people with MS.

\section{Pediatrics}

Along with traditional physiotherapy approaches (Bobath/NDT, Vojta method, and conventional physiotherapy interventions), resistance training, body weight supported treadmill 
training, and pool therapy, WBV is now comprised in a new physiotherapy concept "On your feet" used in children with bilateral spastic cerebral palsy. The therapy combines the bonemass harnessing approach of WBV and individually adjusted WBV settings (vibration amplitude: 0-3.9 mm, frequency: 5-25 Hz). After 6 months of training, bone mineral density, muscle force, and gross motor function all improved significantly in children diagnosed with spastic quadriplegia or diplegia. WBV training is not a part of the standard cerebral palsy rehabilitation, but the researchers encourage its implementation in the rehabilitation procedure (61).

Pediatric therapists tend to select vibration platforms with central axis; the opposite sides of the oscillatory plate rise and fall alternately $(44,57,60)$, which is consistent with the guidelines of the "On your feet" concept (61). Exercises on a vibration platform are safe, feasible, and well tolerated by children with neurological disorders $(44,57,60)$ as confirmed by high compliance in children with cerebral palsy (adherence rate of 78-94\%) (57).

According to the most recent reports, side-alternating vibration therapy is safe and well tolerated among children with Duchenne muscular dystrophy $(44,60)$. The absence of significant changes in serum creatine kinase, a marker of muscle damage, indicates no adverse effects of WBV on body muscles $(44,60)$. Some other authors observed a $56 \%$ increase in creatine kinase in children with Duchenne muscular dystrophy after the first day of vibration training (69). Since the temporary increase in creatine kinase was not related to clinical symptoms or deterioration, the researchers attributed it to muscle reaction to a new stimulus and/or stretching exercises. When treating children with Duchenne muscular dystrophy, Söderpalm et al. (60) used a 12-week program of side-alternating vibration training (frequency in the range of 16-24 Hz and peak-to-peak displacement of $4 \mathrm{~mm}$; exposure 2-3 times a week). No significant changes were observed with respect to bone mass, muscle density, muscle strength, and biochemical markers of bone and mineral metabolism. Nevertheless, the authors emphasize a nonsignificant trend for the bone formation marker, bone-specific alkaline phosphate, to increase after 3 months of WBV, which might indicate an increase in bone formation. Some patients reported subjective improvement during the training period, i.e., easier stair climbing up and down, fewer falls and better balance (69). Although objective measurements did not reveal statistically significant changes in functional tests, muscle strength, and angular degree of dorsiflexion of the ankles after an 8-week vibration training program, the authors recommend the addition of home-based WBV to therapy due to high motivation on the part of the children to perform exercises on the vibration platform (69).

\section{Geriatrics}

Vibration training has been used for prophylactic and therapeutic purposes in geriatric patients although, based on a critical review, Mikhael et al. (42) have questioned the efficacy of WBV in older adults. Rittweger (52) suggests that acute neurophysiological responses to vibration, except for the reflex contraction, are weakened by old age.

The mean age of patients qualified for the studies on older adults or the elderly was different: 83.2 years (2), 67.1 years (7), and 79.6 years (6). The time period of vibration training varied from short, i.e., 8 weeks $(51,72)$ to long-lasting, i.e., 12 months $(7,33)$. The majority of the training programs was carried out 3 times a week $(2,7,42)$. Exercises on a 
vibration platform are considered safe and feasible for older individuals $(18,49,71)$; numerous researchers also emphasize the beneficial effect of WBV on physical and functional performance thereof $(7,33,71)$.

Vibration training enhances cardiorespiratory effort in older people. Although, depending on exercise intensity, heart rate increased by $62-80 \%$ (7), WBV training participants did not complain of physical exertion as opposed to those assigned to the conventional fitness training program. In the study of Perchthaler et al. (49), the subjectively perceived exertion of WBV exercises ranged between 7 and 13 on the 20 -point Borg scale.

Cristi et al. (18) observed that WBV training increased physical performance of older adults without altering the levels of inflammatory markers. According to the recent reports, WBV training lasting several week increases muscle strength (42), improves muscle quality characteristics (33), static balance (51), and VO2max (7), increases the height of a counter movement jump (49), and maximal voluntary isometric contraction (18). Other authors also noted similar beneficial effects of traditional resistance or aerobic training and WBV on physical performance of older individuals $(7,33)$.

Not all researchers confirm the beneficial effect of WBV on the aging body $(2,6,49)$. Several weeks of vibration training did not reduce fall risk $(2,6)$; it also did not affect postural control as evaluated by computerized posturography (6), lower leg muscle cross-sectional area (42), isokinetic maximal strength, mean power, and work values in knee extension or flexion (49). Beaudart et al. (2) hypothesize that no impact of vibration training on the risk of falls might have been due to exposure parameters, i.e., short duration of a single exercise session (15 s) and low vibration intensity $(30 \mathrm{~Hz} / 2 \mathrm{~mm})$.

Bogaerts et al. (7) emphasize that, compared to conventional resistance training, WBV is more pleasant for older individuals, exercise duration is shorter and movement technique uncomplicated. A 3- and 12-month training was discontinued by $19.4 \%$ and $23 \%$ of the participants in the study of Beaudart et al. (2) and Bogaerts et al. (7), respectively. A 1-year post-intervention follow-up revealed that the majority of those who discontinued WBV training had lost most of their gains in muscle volume (33).

Osteoporosis is among the adverse processes associated with aging and postmenopause. There are literature reports on the use of WBV in postmenopausal osteopenic women and in prevention of osteoporosis $(62,66)$. Mostly postmenopausal women $(36,62,66)$ and quite rarely older men (27) were enrolled in the most recent research studies. Not all women had been diagnosed with osteopenia or osteoporosis $(36,66)$. The density of the hip bone (68), lumbar spine (36), or the tibia (62) was assessed with dual-energy X-ray absorptiometry and/or peripheral quantitative computed tomography $(36,62,68)$. There were several differences between training programs: both vertical (66) and side-alternating WBV (62) were used; training duration ranged from 11 weeks (27) to 9 months (62); uniform vibration parameters were applied (66) or, if needed, changed according to overload principle (62, 68). Study participants most often performed static and/or dynamic exercises, including squats and standing $(27,62,68)$. The importance of correct training program selection (frequency of exposure) was emphasized by Turner et al. (66); only one among WBV training protocols used in their study led to a meaningful change in bone turnover. Of clinical importance might be that 8-week low-frequency, low-magnitude vibration training resulted in a significant reduction in N-telopeptide $\mathrm{X} /$ Creatinine, which is a marker of bone resorption (66). However, the most recent research of Gómez-Cabello et al. (27) did not confirm the beneficial effects of WBV on the anabolic activity of bone tissue. Verschueren et al. (68), on the other hand, found a significant $0.75 \%$ increase in total-hip BMD while 
Lai et al. (36) noted a 2.032\% increase in lumbar BMD after a WBV program. It has been emphasized, however, that a similar effect was obtained in women with vitamin D supplementation (68) or balance training (62).

\section{Orthopedics}

WBV training is considered safe and effective in rehabilitation after injury of the ACL $(4,25$, 43). The patients who tore their ACL, with or without concomitant meniscal injury, can start the vibration therapy as early as two weeks after surgery (4). Two types of vibration platforms were used in the study: vertical vibration $(25,43)$ and side-alternating platforms $(4)$, set at a frequency range $30-50 \mathrm{~Hz}$ and $10-30 \mathrm{~Hz}$, respectively. There has been good evidence for effectiveness of WBV training in the ACL-rehabilitation protocols. The literature reports an improvement in the accuracy of knee joint proprioception and postural stability in athletes after ACL reconstruction (43) and beneficial impact on muscle performance (25) as a result of vibration training. Study of Berschin et al. (4) revealed that after ten weeks of vibration training, the WBV group reached equal results compared to control group with standard rehabilitation exercise protocol in terms of knee joint stability, subjective quality of life and muscle strength; however, the experimental group showed significant improvement in postural control (4).

WBV training is a safe method for rehabilitation of knee osteoarthritis $(64,70)$ as no adverse effects are reported by the patients (70). Compared to regular strength training, WBV causes lower loads on the affected joint due to low joint dynamics during exercise (64). However, the results regarding the application of vibration training in patients with knee osteoarthritis remain equivocal. An 8-week WBV-exercise program on a balance board with a built-in vibrating device resulted in knee proprioception improvement as assessed based on threshold for detection of passive movement (64). Long-term vibration training (24 weeks, 5 days/week) in combination with quadriceps resistance exercise has benefits on functions and quality of life in patients with knee osteoarthritis (70). According to Park et al. (48), there was no significant difference between the experimental group (WBV and home-based exercise) and the control group (home-based exercise) on quadriceps muscle strength after 8 weeks of intervention.

Knee joint arthroplasty is an intervention for severe symptomatic osteoarthritis of the knee joint. WBV training may be used in the rehabilitation of individuals after total knee arthroplasty, although it did not result in greater improvements in muscle strength, muscle activation, or mobility than traditional progressive resistance exercise (30).

Based on available literature reports, it can be concluded that exposure to high levels of WBV is associated with higher risk of low back pain and sciatica (11). Nevertheless, several researchers investigated whether WBV was feasible for patients with chronic low back pain $(19,50)$. The literature review indicates that the effectiveness of WBV as a treatment for low back pain remains equivocal (50). The study of del Pozo-Cruz et al. (19), on the other hand, showed statistically significant improvement in the main outcome measures for chronic nonspecific low back pain after a 12-week low-frequency vibrating board therapy. The platform generated side-alternating oscillations of the whole body; the training was performed twice a week. After the completion of the study, the Oswestry Index (the percentage of disability attributable to back pain) improved by $25.15 \%$. No adverse effects were noted in the WBV group as confirmed by $100 \%$ compliance with the treatment. 
Inappropriately used WBV may have harmful effects on the human body (13). Contraindications to WBV therapy must be taken into consideration; hence, doctors and physiotherapists should be consulted prior to the implementation of vibration exposure.

\section{Conclusion}

The complexity of the processes to make up for functional and structural losses as well as divergence in WBV training protocols used in patients diagnosed with different dysfunctions causes doubts concerning the otherwise interesting and promising physiotherapeutic WBV. The knowledge on the subject is still unsatisfactory, and the published results are inconsistent. The literature contains reports presenting beneficial effects of WBV, no effects or lack of differences between the study and control groups irrespective of the exposure protocol used. Therefore, further multidirectional and multicenter, randomized post-intervention follow-up studies are needed to determine the ultimate effects of WBV in patients with different dysfunctions. Nevertheless, literature data also indicate that, despite of its ultimate effects, WBV is a safe, less tiring, and less time-consuming modality of rehabilitation exercises than a standard muscle strengthening protocol.

\section{REFERENCES}

1. Arias P, Chouza M, Vivas J, Cudeiro J: Effect of whole body vibration in Parkinson's disease: a controlled study. Mov. Disord. 24, 891-898 (2009)

2. Beaudart C, Maquet D, Mannarino M, Buckinx F, Demonceau M, Crielaard JM, Reginster JY, Bruyère O: Effects of 3 months of short sessions of controlled whole body vibrations on the risk of falls among nursing home residents. BMC Geriatr. 6, 42 (2013)

3. Belavý D, Miokovic T, Armbrecht G, Rittweger J, Felsenberg D: Resistive vibration exercise reduces lower limb muscle atrophy during 56-day bed-rest. J. Musculoskelet. Neuronal Interact. 9, 225-235 (2009)

4. Berschin G, Sommer B, Behrens A, Martin Sommer H: Whole body vibration exercise protocol versus a standard exercise protocol after ACL reconstruction: a clinical randomized controlled trial with short term follow-up. J. Sports Sci. Med. 13, 580-589 (2014)

5. Boeselt T, Nell C, Kehr K, Holland A, Dresel M, Greulich T, Tackenberg B, Kenn K, Boeder J, Klapdor B, Kirschbaum A, Vogelmeier C, Alter P, Koczulla R: Whole-body vibration therapy in intensive care patients: a feasibility and safety study. J. Rehabil. Med. 48, 316-321 (2016)

6. Bogaerts A, Delecluse C, Boonen S, Claessens AL, Milisen K, Verschueren SM: Changes in balance, functional performance and fall risk following whole body vibration training and vitamin $\mathrm{D}$ supplementation in institutionalized elderly women. A 6-month randomized controlled trial. Gait Posture 33, 466-472 (2011)

7. Bogaerts AC, Delecluse CE, Claessens AL, Troosters T, Boonen S, Verschueren SM: Effects of whole body vibration training on cardiorespiratory fitness and muscle strength in older individuals (a 1-year randomised controlled trial). Age Ageing 38, 448-454 (2009)

8. Broekmans T, Roelants M, Alders G, Feys P, Thijs H, Eijnde BO: Exploring the effects of a 20-week wholebody vibration training programme on leg muscle performance and function in persons with multiple sclerosis. J. Rehabil. Med. 42, 866-872 (2010)

9. Brogårdh C, Flansbjer U, Lexell J: No specific effect of whole-body vibration training in chronic stroke: a double-blind randomized controlled study. Arch. Phys. Med. Rehabil. 93, 253-258 (2012)

10. Brunner S, Brunner D, Winter H, Kneidinger N: Feasibility of whole body vibration as an early inpatient rehabilitation tool after lung transplantation - a pilot study. Clin. Transplant. 30, 93-98 (2016)

11. Burström L, Nilsson T, Wahlström J: Whole-body vibration and the risk of low back pain and sciatica: a systematic review and meta-analysis. Int. Arch. Occup. Environ. Health 88, 403-418 (2014)

12. Cardinale M, Wakeling J: Whole body vibration exercise: are vibrations good for you? Br. J. Sports Med. 39 , 585-589 (2005) 
13. Chanou K, Gerodimos V, Karatrantou K, Jamurtas A: Whole-body vibration and rehabilitation of chronic diseases: a review of the literature. J. Sports Sci. Med. 11, 187-200 (2012)

14. Chouza M, Arias P, Viñas S, Cudeiro J: Acute effects of whole-body vibration at 3, 6, and $9 \mathrm{~Hz}$ on balance and gait in patients with Parkinson's disease. Mov. Disord. 26, 920-921 (2011)

15. Claerbout M, Gebara B, Ilsbroukx S, Verschueren S, Peers K, Van Asch P, Feys P: Effects of 3 weeks' whole body vibration training on muscle strength and functional mobility in hospitalized persons with multiple sclerosis. Mult. Scler. 18, 498-505 (2012)

16. Cochrane DJ: The potential neural mechanisms of acute indirect vibration. J. Sports Sci. Med. 10, 19-30 (2011)

17. Cochrane DJ, Stannard SR, Sargeant AJ, Rittweger J: The rate of muscle temperature increases during acute whole-body vibration exercise. Eur. J. Appl. Physiol. 103, 441-448 (2008)

18. Cristi C, Collado PS, Márquez S, Garatachea N, Cuevas MJ: Whole body vibration training increases physical fitness measures without alteration of inflammatory markers in older adults. Eur. J. Sport Sci. 14, 611-619 (2014)

19. del Pozo-Cruz B, Hernández Mocholí MA, Adsuar JC, Parraca JA, Muro I, Gusi N: Effects of whole body vibration therapy on main outcome measures for chronic non-specific low back pain: a single-blind randomized controlled trial. J. Rehabil. Med. 43, 689-694 (2011)

20. Di Loreto C, Ranchelli A, Lucidi P, Murdolo G, Parlanti N, De Cicco A, Tsarpela O, Annino G, Bosco C, Santeusanio F, Bolli GB, De Feo P: Effects of whole-body vibration exercise on the endocrine system of healthy men. J. Endocrinol. Invest. 27, 323-327 (2004)

21. Dickin D, Faust K, Wang H, Frame J: The acute effects of whole-body vibration on gait parameters in adults with cerebral palsy. J. Musculoskelet. Neuronal Interact. 13, 19-26 (2013)

22. Ebersbach G, Edler D, Kaufhold O, Wissel J: Whole body vibration versus conventional physiotherapy to improve balance and gait in Parkinson's disease. Arch. Phys. Med. Rehabil. 89, 399-403 (2008)

23. Ebrahimi A, Eftekhari E, Etemadifar M: Effects of whole body vibration on hormonal \& functional indices in patients with multiple sclerosis. Indian J. Med. Res. 142, 450-458 (2015)

24. Eklund G, Hagbarth K: Normal variability of tonic vibration reflex in man. Exp. Neurol. 16, 80-92 (1966)

25. Fu CL, Yung SH, Law KY, Leung KH, Lui PY, Siu HK, Chan KM: The effect of early whole-body vibration therapy on neuromuscular control after anterior cruciate ligament reconstruction: a randomized controlled trial. Am. J. Sports Med. 41, 804-814 (2013)

26. Gaßner H, Janzen A, Schwirtz A, Jansen P: Random whole body vibration over 5 weeks leads to effects similar to placebo: a controlled study in Parkinson's disease. Parkinson's Dis. 2014, 386495 (2014)

27. Gómez-Cabello A, González-Agüero A, Morales S, Ara I, Casajús JA, Vicente-Rodríguez G: Effects of a shortterm whole body vibration intervention on bone mass and structure in elderly people. J. Sci. Med. Sport 17, 160164 (2014)

28. Guo C, Mi X, Liu S, Yi W, Gong C, Zhu L, Machado S, Yuan TF, Shan C: Whole body vibration training improves walking performance of stroke patients with knee hyperextension: a randomized controlled pilot study. CNS Neurol. Disord. Drug Targets 14, 1110-1115 (2015)

29. Jackson KJ, Merriman HL, Vanderburgh PM, Brahler CJ: Acute effects of whole-body vibration on lower extremity muscle performance in persons with multiple sclerosis. J. Neurol. Phys. Ther. 32, 171-176 (2008)

30. Johnson AW, Myrer JW, Hunter I, Feland JB, Hopkins JT, Draper DO, Eggett D: Whole-body vibration strengthening compared to traditional strengthening during physical therapy in individuals with total knee arthroplasty. Physiother. Theory Pract. 26, 215-225 (2010)

31. Jordan J, Norris S, Smith D, Herzog W: Vibration training: an overview of the area, training consequences, and future considerations. J. Strength Cond. Res. 19, 459-466 (2005)

32. Kaut O, Allert N, Coch C, Paus S, Grzeska A, Minnerop M, Wüllner U: Stochastic resonance therapy in Parkinson's disease. NeuroRehabilitation 28, 353-358 (2011)

33. Kennis E, Verschueren S, Bogaerts A, Coudyzer W, Boonen S, Delecluse C: Effects of fitness and vibration training on muscle quality: a 1-year postintervention follow-up in older men. Arch. Phys. Med. Rehabil. 94, 910918 (2013)

34. Krol P, Piecha M, Slomka K, Sobota G, Polak A, Juras G: The effect of whole-body vibration frequency and amplitude on the myoelectric activity of vastus medialis and vastus lateralis. J. Sports Sci. Med. 10, 169-174 (2011)

35. Kvorning T, Bagger M, Caserotti P, Madsen K: Effects of vibration and resistance training on neuromuscular and hormonal measures. Eur. J. Appl. Physiol. 96, 615-625 (2006) 
36. Lai CL, Tseng SY, Chen CN, Liao WC, Wang CH, Lee MC, Hsu PS: Effect of 6 months of whole body vibration on lumbar spine bone density in postmenopausal women: a randomized controlled trial. Clin. Interv. Aging 8, 1603-1609 (2013)

37. Lau R, Yip S, Pang M: Whole-body vibration has no effect on neuromotor function and falls in chronic stroke. Med. Sci. Sports Exerc. 44, 1409-1418 (2012)

38. Liao LR, Ng GY, Jones AY, Pang MY: Cardiovascular stress induced by whole-body vibration exercise in individuals with chronic stroke. Phys. Ther. 95, 966-977 (2015)

39. Liu P, Brummel-Smith K, Ilich J: Aerobic exercise and whole-body vibration in offsetting bone loss in older adults. J. Aging Res. 2011, 379674 (2011)

40. Marín PJ, Ferrero CM, Menéndez H, Martín J, Herrero AJ: Effects of whole-body vibration on muscle architecture, muscle strength, and balance in stroke patients: a randomized controlled trial. Am. J. Phys. Med. Rehabil. 92, 881-888 (2013)

41. Mason RR, Cochrane DJ, Denny GJ, Firth EC, Stannard SR: Is 8 weeks of side-alternating whole-body vibration a safe and acceptable modality to improve functional performance in multiple sclerosis? Disabil. Rehabil. 34, 647-654 (2012)

42. Mikhael M, Orr R, Amsen F, Greene D, Singh M: Effect of standing posture during whole body vibration training on muscle morphology and function in older adults: a randomised controlled trial. BMC Geriatr. 10, 74 (2010)

43. Moezy A, Olyaei G, Hadian M, Razi M, Faghihzadeh S: A comparative study of whole body vibration training and conventional training on knee proprioception and postural stability after anterior cruciate ligament reconstruction. Br. J. Sports Med. 42, 373-378 (2008)

44. Myers KA, Ramage B, Khan A, Mah JK: Vibration therapy tolerated in children with Duchenne muscular dystrophy: a pilot study. Pediatr. Neurol. 51, 126-129 (2014)

45. Ness L, Field-Fote E: Effect of whole-body vibration on quadriceps spasticity in individuals with spastic hypertonia due to spinal cord injury. Restor. Neurol. Neurosci. 27, 621-631 (2009)

46. Ness LL, Field-Fote EC: Whole-body vibration improves walking function in individuals with spinal cord injury: a pilot study. Gait Posture 30, 436-440 (2009)

47. Pang MY, Lau RW, Yip SP: The effects of whole-body vibration therapy on bone turnover, muscle strength, motor function, and spasticity in chronic stroke: a randomized controlled trial. Eur. J. Phys. Rehabil. Med. 49, 439-450 (2013)

48. Park YG, Kwon BS, Park JW, Cha DY, Nam KY, Sim KB, Chang J, Lee HJ: Therapeutic effect of whole body vibration on chronic knee osteoarthritis. Ann. Rehabil. Med. 37, 505-515 (2013)

49. Perchthaler D, Grau S, Hein T: Evaluation of a six-week whole body vibration intervention on neuromuscular performance in older adults. J. Strength Cond. Res. 29, 86-89 (2015)

50. Perraton L, Machotka Z, Kumar S: Whole-body vibration to treat low back pain: fact or fad? Physiother. Can. 63, 88-93 (2011)

51. Rees S, Murphy A, Watsford M: Effects of whole body vibration on postural steadiness in an older population. J. Sci. Med. Sport 12, 440-444 (2009)

52. Rittweger J: Vibration as an exercise modality: how it may work, and what its potential might be. Eur. J. Appl. Physiol. 108, 877-904 (2010)

53. Rittweger J, Schiessl H, Felsenberg D: Oxygen uptake during whole body vibration exercise: comparison with squatting as a slow voluntary movement. Eur. J. Appl. Physiol. 86, 169-173 (2001)

54. Ritzmann R, Gollhofer A, Kramer A: The influence of vibration type, frequency, body position and additional load on the neuromuscular activity during whole body vibration. Eur. J. Appl. Physiol. 113, 1-11 (2013)

55. Ritzmann R, Kramer A, Bernhardt S, Gollhofer A: Whole body vibration training - improving balance control and muscle endurance. PLoS One 9, e89905 (2014)

56. Rosenberger A, Liphardt AM, Bargmann A, Müller K, Beck L, Mester J, Zange J: EMG and heart rate responses decline within 5 days of daily whole body vibration training with squatting. PLoS One 9, e99060 (2014)

57. Ruck J, Chabot G, Rauch F: Vibration treatment in cerebral palsy: a randomized controlled pilot study. J. Musculoskelet. Neuronal Interact. 10, 77-83 (2010)

58. Schyns F, Paul L, Finlay K, Ferguson C, Noble E: Vibration therapy in multiple sclerosis: a pilot study exploring its effects on tone, muscle force, sensation and functional performance. Clin. Rehabil. 23, 771-781 (2009)

59. Silva A, Dias M, Calixto R Jr, Carone A, Martinez B, Silva A, Honorato D: Acute effects of whole-body vibration on the motor function of patients with stroke: a randomized clinical trial. Am. J. Phys. Med. Rehabil. 93, 310-319 (2014) 
60. Söderpalm AC, Kroksmark AK, Magnusson P, Karlsson J, Tulinius M, Swolin Eide D: Whole body vibration therapy in patients with Duchenne muscular dystrophy - a prospective observational study. J. Musculoskelet. Neuronal Interact. 13, 13-18 (2013)

61. Stark C, Nikopoulou-Smyrni P, Stabrey A, Semler O, Schoenau E: Effect of a new physiotherapy concept on bone mineral density, muscle force and gross motor function in children with bilateral cerebral palsy. J. Musculoskelet. Neuronal Interact. 10, 151-158 (2010)

62. Stolzenberg N, Belavý DL, Beller G, Armbrecht G, Semler J, Felsenberg D: Bone strength and density via pQCT in post-menopausal osteopenic women after 9 months resistive exercise with whole body vibration or proprioceptive exercise. J. Musculoskelet. Neuronal Interact. 13, 66-76 (2013)

63. Tankisheva E, Bogaerts A, Boonen S, Feys H, Verschueren S: Effects of intensive whole-body vibration training on muscle strength and balance in adults with chronic stroke: a randomized controlled pilot study. Arch. Phys. Med. Rehabil. 95, 439-446 (2014)

64. Trans T, Aaboe J, Henriksen M, Christensen R, Bliddal H, Lund H: Effect of whole body vibration exercise on muscle strength and proprioception in females with knee osteoarthritis. Knee 16, 256-261 (2009)

65. Tsopani D, Dallas G, Tsiganos G, Papouliakos S, Di Cagno A, Korres G, Riga M, Korres S: Short-term effect of whole-body vibration training on balance, flexibility and lower limb explosive strength in elite rhythmic gymnasts. Hum. Mov. Sci. 33, 149-158 (2014)

66. Turner S, Torode M, Climstein M, Naughton G, Greene D, Baker MK, Fiatarone Singh MA: A randomized controlled trial of whole body vibration exposure on markers of bone turnover in postmenopausal women. J. Osteoporos. 2011, 710387 (2011)

67. Uszynski MK, Purtill H, Donnelly A, Coote S: Comparing the effects of whole-body vibration to standard exercise in ambulatory people with multiple sclerosis: a randomised controlled feasibility study. Clin. Rehabil. 30, 657-668 (2016)

68. Verschueren S, Bogaerts A, Delecluse C, Claessens A, Haentjens P, Vanderschueren D, Boonen S: The effects of whole-body vibration training and vitamin $\mathrm{D}$ supplementation on muscle strength, muscle mass, and bone density in institutionalized elderly women: a 6-month randomized, controlled trial. J. Bone Miner. Res. 26, 42-49 (2011)

69. Vry J, Schubert IJ, Semler O, Haug V, Schönau E, Kirschner J: Whole body vibration training in children with Duchenne muscular dystrophy and spinal muscular atrophy. Eur. J. Paediatr. Neurol. 18, 140-149 (2014)

70. Wang P, Yang L, Liu C, Wei X, Yang X, Zhou Y, Jiang H, Lei Z, Reinhardt JD, He C: Effects of whole body vibration exercise associated with quadriceps resistance exercise on functioning and quality of life in patients with knee osteoarthritis: a randomized controlled trial. Clin. Rehabil. doi: 10.1177/0269215515607970, first published on October 1 (2015)

71. Wolfsegger T, Assar H, Topakian R: 3-week whole body vibration does not improve gait function in mildly affected multiple sclerosis patients - a randomized controlled trial. J. Neurol. Sci. 347, 119-123 (2014)

72. Zhang L, Weng C, Liu M, Wang Q, Liu L, He Y: Effect of whole body vibration exercise on mobility, balance ability and general health status in frail elderly patients: a pilot randomized controlled trial. Clin. Rehabil. 28, 59-68 (2014) 